\title{
ANÁLISIS DE ALGUNAS ESTRATEGIAS ICÓNICAS EN LA CONMEMORACIÓN DE LA EFEMÉRIDE DEL “30 DE NOVIEMBRE” EN ESCUELAS DE MISIONES, ARGENTINA
}

\author{
Analysis of some iconic strategies in commemoration of the ephemerides of \\ "November 30th" at schools from Misiones, Argentina
}

María Itatí Rodríguez*

\begin{abstract}
Resumen
Los actos patrios escolares proponen distintos modos de poner en escena las memorias (sociales, públicas). En el presente artículo nos proponemos reflexionar y analizar distintos mecanismos semióticos que operan dentro de este formato como un complejo mnemo-semiótico y comunicativo entendido como dispositivo ritual performativo. Proponemos un análisis desde algunas estrategias icónicas en la puesta en escena de actos escolares que conmemoran la efeméride del 30 de noviembre "Día de la Bandera de Misiones" y "Día del Prócer Misionero Andrés Guacurarí y Artigas" en escuelas primarias públicas de la provincia de Misiones, Argentina. En este sentido, analizamos tres canciones observadas durante nuestra instancia de trabajo de campo doctoral (2013-2015). Ofrecemos algunas herramientas teórico-metodológicas para la reflexión y el análisis de mecanismos de memoria que proponen imaginar determinados sentidos y significaciones sobre las identidades histórico-políticas que se encuentran en constante producción y construcción en la provincia de Misiones.
\end{abstract}

$$
<\text { Formato comunicativo }><\text { Semiótica }><\text { Ícono }><\text { Efeméride }>
$$

\begin{abstract}
The school patriotic acts involve different ways of putting in scene memories (social, public). In this article we analyze different semiotic mechanisms that operate within this format as a mnemosemiotic and communicative complex as performative ritual device. We propose an analysis from some iconic strategies in the putting in scene of school events commemorating the ephemerides of November 30 "Misiones flag day" and "Day of the hero missionary Andrés Guacurarí y Artigas" in public primary schools in the province of Misiones, Argentina. In this sense, we analyze three songs recorded during our instance of doctoral fieldwork (2013-2015). We offer some theoretical and methodological tools for reflection and analysis of mechanisms of memory proposed by imagining certain senses and meanings of the historicalpolitical identities that are in constant production and construction in the province of Misiones.
\end{abstract}

$$
<\text { Communicative format }><\text { Semiotics }><\text { Icon }><\text { Ephemeride }>
$$

Recibido: 15/02/2017 //Aceptado: 15/03/2017

\footnotetext{
* Doctora en Comunicación, Facultad de Periodismo y Comunicación Social - Universidad Nacional de La Plata. Becaria postdoctoral del Consejo Nacional de Investigaciones Científicas y Tecnológicas (CONICET) en el Instituto de Ciencias Sociales y Humanas (UNaM-CONICET). itatirodriguez@yahoo.com.ar
} 


\section{Introducción}

Los actos patrios escolares sobre/vividos como colectivos son necesariamente actos políticos construidos en una complejidad de sentidos. La provincia de Misiones - de modo institucional- transita una re-actualización de las memorias colectivas/públicas e identidades, continúa un itinerario para la construcción de una historia provincial "propia".

Contamos con una importante trayectoria de investigaciones que -desde distintas disciplinas y campos de estudio- abordaron la cuestión de las efemérides y los actos patrios escolares. En este sentido, sobre la génesis de estos rituales en Argentina en relación con la construcción del proyecto nacional estatal (Bertoni 2001; Díaz, 2009; Dussel, 2007; Dussel y Southwell, 2009; Escudé, 1990), sobre su rol en el orden escolar (Milstein y Mendes, 1999). Asimismo, se destacan trabajos que abordan los rituales de celebración en los centenarios y bicentenarios (Batticuore y Gayol, 2011; Carrión, 2012), sobre la enseñanza de la historia en las escuelas (Carretero, Rosa y González, 2006), sobre la construcción de las imágenes en la relación con la nación (Caggiano, 2007, 2013), sobre las representaciones de las comunidades afrodescendientes en Argentina (Ocoró Loango, 2009, 2010); sobre la construcción de la nación en los textos y manuales escolares (García, 1999, 2012; Romero, 2004). Por su parte, se cuentan con estudios desde diversos enfoques: desde la psicología cultural (Carretero 2007, Carretero y Kriger 2010), desde la historia (Goldman, 2009; Ortemberg 2013), desde la antropología (Blázquez, 2011, 2012), desde la semiótica (Finol, 2002, 2006; Magli, 2002). También podemos señalar trabajos desde las perspectivas locales, provinciales, de regiones argentinas, como por ejemplo: sobre el caso patagónico (Aranciaga, 2004; Torres, 2004), o la provincia de Misiones (Camblong, 2009, 2014; De Haro, 2005; Grimson, 2002; Jaquet, 2005; Rodríguez, 2011, 2015, 2016; Vain 1997).

Desde un análisis semiótico-comunicativo, entendemos a la conmemoración del acto escolar como formato, esto es un complejo mnemosemiótico y comunicativo (García, 2004, 2012), entendido como dispositivo ritual performativo (Augé, 1995), que logra poner en circulación todo un complejo sistema de sentidos que se refieren a una memoria común, a un pasado fundacional de la nación. El formato como un productor de semiosis y de memoria que reproduce, negocia, confronta, disputa saberes, poderes, sentidos, y que redefine el curso del proceso comunicativo (García, 2004). Los actos escolares entendidos como formatos nos permiten comprender cómo a partir de determinadas matrices semióticas-comunicativas se siguen determinadas prácticas que implican tensiones, negociaciones por el sentido.

Los actos escolares mediante las efemérides proponen la conmemoración del aniversario de un hecho o personaje histórico. Consideramos que más allá de su significado etimológico, las efemérides en clave de conmemoración no son solamente 'de un solo día' debido a que implican una trama compleja de sentidos y significados que se re-actualizan en cada ocasión. Proponen todo un cronograma de actividades: algunas de ellas tienen más relevancia que otras, algunas parecieran estar cristalizadas y otras surgen en los calendarios pujando por un lugar. En este sentido, los actos patrios escolares como actos de memoria (Halbwachs, 1950; Lotman, 1998; Middleton \& 
Derek, 1992; Nora, 2008; Ricoeur, 1999) colocan en escena determinados momentos y personajes 'dignos' de recordar, dejando al olvido a otros, promoviendo una producción y construcción de las memorias (sociales, públicas).

El 30 de noviembre se recuerda en todas las escuelas misioneras a la bandera provincial y a la figura de Andrés Guacurarú y Artigas, declarado en 2012 como "prócer misionero" (Ley Provincial VI N.155/12). Mediante distintas estrategias -como es la implementación de una efeméride y acto escolar- este personaje se instala como la figura histórica más importante de la provincia. Andresito -sobrenombre que adquirió a causa de su baja estatura, rasgo común entre la gran mayoría de los pueblos americanos- fue un indio guaraní, colaborador de José Gervasio Artigas -quien lo apadrinó y lo adoptó como hijo cuando éste se encomendó a la causa de la Liga de los Pueblos Libres ${ }^{1}$-, comandó la Provincia Grande de las Misiones entre 1811 y 1822. Asimismo, en esta fecha también se celebra el "Día de Bandera de la Provincia de Misiones", sus colores se fundamentan en el estandarte que el "héroe local" habría enarbolado como una de sus primeras gestiones como Comandante General de Misiones. A diferencia de otras efemérides -por ejemplo la del 25 de mayo "Día de la Revolución de mayo"- el 30 de noviembre se incorpora al calendario escolar desde mediados de la década de 1990, lapso de tiempo breve en relación a otras efemérides que se instauraron prácticamente al mismo tiempo que la inauguración de las escuelas primarias públicas en Argentina a finales del siglo XIX (Rodríguez, 2016).

En Misiones los actos escolares se encuentran reglamentados por el Calendario Escolar Permanente del Consejo General de Educación (Res. N.842/2006) que se presenta como un cronograma escolar básico y unificado para las escuelas y su desarrollo curricular. Según este documento, cada efeméride adquiere determinado modo de proceder denominado "forma" que las posiciona en un orden de jerarquía del 1 al 4, designando de una mayor a una menor importancia y organización en su realización. El 30 de noviembre -implementada solamente en la provincia de Misiones- compone una de las cuatro efemérides con la forma más importante denominada como "Forma I" de carácter obligatoria, con suspensión de actividades áulicas y presencia de toda la organización escolar.

En el presente artículo analizamos parte de los materiales recabados durante el trabajo de campo en el marco de la investigación de nuestra tesis doctoral ${ }^{2}$, el cual consistió de un registro y análisis de actos patrios celebrados en escuelas primarias públicas de la ciudad de Posadas (2013 y 2015) y de Puerto Iguazú (2014). Proponemos

1 Esta Liga Federal fue una confederación de provincias aliadas dentro de las Provincias Unidas del Río de la Plata, liderada por José Gervasio Artigas (1764-1850); fue constituida por las provincias de Córdoba, Corrientes, Entre Ríos, la Provincia Oriental, Santa Fe y los pueblos de Misiones.

2 En un sentido amplio, nuestra investigación indaga sobre los procesos actuales de construcción y producción de identidades colectivas histórico-políticas (nacionales y locales) en relación a los mecanismos de memoria presentes en las efemérides y actos escolares de escuelas primarias públicas de la provincia de Misiones En este contexto, siguiendo los objetivos generales de nuestro estudio, trabajamos con los actos escolares Forma I: el 25 de mayo "Día de la Revolución de Mayo", 20 de junio "Día de la Bandera", 9 de julio "Día de la Independencia" y 30 de noviembre. 
reflexionar y analizar distintos mecanismos semióticos, con especial énfasis en esta oportunidad, en el signo-ícono- en relación a su objeto (efeméride del 30 de noviembre). En la comunicación concreta, la semiosis se vale de tres regímenes, tres formas que se entrecruzan, dialogan, conviven, se superponen siempre: lo icónico, lo indicial y lo simbólico. Estas formas se encuentran siempre presentes en la comunicación, ya que no podría producirse significación sin ellas. En el presente texto analizaremos el formato proponiendo un movimiento de análisis semiótico-comunicativo que entiende las canciones que se cantan para conmemorar la efeméride en tanto íconos, los cuales nos permiten imaginar determinados sentidos sobre Misiones. Sin pretender agotar el análisis de las estrategias puestas en obra en este objeto de estudio, consideramos necesario advertir que esta entrada de análisis no se encuentra cerrada, ya que como todo proceso de semiosis nos ofrecen aperturas y movimientos.

\section{Una efeméride misionera}

Podemos pensar la producción, selección, e implementación 'oficial' de una efeméride -local, como lo es el 30 de noviembre- dentro mecanismos amplios y complejos. En este sentido, los procesos de construcción de una historia propia -con sus personajes y hechos históricos- en la provincia de Misiones poseen larga data y se fueron gestando previos a la provincialización de Misiones en la década del 50 en el cual distintos sectores intelectuales y políticos de la época procuraban acceder a los derechos que implicaba (volver a) ser una Provincia Argentina (Jaquet, 2005). Logrado el objetivo en 1953 mediante la Ley 14294 sancionada durante el gobierno de Juan Domingo Perón, se comienzan a transitar otros periodos y contextos donde se localizan algunos de los sentidos que merodean la idea de "ser misionero".

En la actualidad, ya transcurridos poco más de 60 años de su provincialización, podemos decir que los relatos históricos-políticos no están escritos de una vez para siempre, son producto de una sociedad y de su tiempo. Las preguntas que se hacen están sujetas "a revisiones y refleja las tensiones políticas, culturales y sociales del momento en que se lo formula. Sin embargo, no es solamente el acuerdo sobre la efeméride histórica, sino la historia posterior la que también influye sobre esta definición" (Gutman, 2012).

En tiempos de globalización y del vaciamiento integral de los recursos, economías y culturas soberanas de los países periféricos, en especial de los latinoamericanos, Carretero señala que existen dos opciones para hacerle frente a estos procesos. Por un lado, "aferrarse a la identidad común, por medio de la ritualización e incluso la reificación de los relatos y los símbolos (...) La segunda opción imprime un compromiso y un riesgo mayores, porque consiste en reconstruir la identidad en una clave que se oponga radicalmente (pero no reactivamente) a la del oficialismo y sus tradiciones, de acuerdo con nuevos objetivos y desde una perspectiva de otros sujetos históricos" (Carretero, 2007: 166). La puesta en escena de la efeméride del 30 de noviembre navegaría entre estas dos opciones, procurando una reactualización de lo que implicaría la misioneridad, es decir un imaginario basado en la supuesta existencia de valores y virtudes del "ser misionero", que fue construido desde un discurso histórico 
centrado en la figura de Andrés Guacurarí como "prócer" o "héroe” local, en el contexto de reivindicación provincialista de la década de 1950 (Jaquet, 2005).

Advertimos necesario delinear algunos de los sentidos que envuelven la idea de "región" o lo "local" en nuestro texto, conceptos también polisémicos y aún fruto de debates y discusiones. La "región" constituye una organización espacio-tiempo vivido, "se presenta como un espacio menos extendido que la nación y más vasto que el que corresponde al espacio social de un grupo y, por consiguiente, de un lugar" (Areces, 2008: 248). Reflexionar sobre la categoría "región" obliga a pensar la trama de relaciones sociales presentes en cronotopos (Bajtín, 1982) determinados que se modifican, que se encuentran en movimiento. En este contexto, los procesos de identificación con una región son el resultado de "la relación entre el 'nosotros' y el contraste de oposición con el 'otro', la referencia a los proyectos políticos y a las conformaciones, la elaboración de contenidos culturales y la vinculación con el contexto histórico" (Areces, 2008: 255). Cuando nos proponemos (re)construir los sentidos sobre una semiosfera (Lotman, 1996, 1998) "misionera", entendemos que el sentido sobre lo local no es unívoco, ya que "resulta de la fragmentación, producida por la des-localización que impone lo global (...) es el lugar que introduce ruido en las redes, distorsiones en el discurso de lo global, a través de las cuales emerge la palabra de otros, de muchos otros" (Martín-Barbero, 2002: 268).

\section{Las categorías: icónico, hábito y creencia}

Trabajamos dentro de los aportes de la Semiótica, entendido como un programa de estudio de toda semiosis posible, y que reside "en la senda (peirceana) hacia la apertura de mundos (posibles)" (García, 2004: 61). Este programa representa un modo de entender el mundo, de comprender la realidad (semiótica). El edificio semiótico propuesto por Peirce, nos permite construir y diseñar herramientas para analizar y comprender distintos procesos comunicativos. En esta oportunidad desplegaremos los sentidos de tres categorías: ícono, hábito y creencia.

El signo establece relaciones consigo mismo, con su objeto y con su interpretante. En esta oportunidad, nos interesa abordar al ícono como un signo, en virtud de su propia cualidad que se refiere al objeto al que denota, "en la medida en que es como esa cosa y en que es usada como signo de ella" (Peirce, 1996: 30) De esta manera, el ícono es la relación resultante "del entrecruzamiento del objeto con la primeridad, en tanto manifiesta la puesta en primer plano de la cualidad entre signo y su objeto" (Coviello, 2014: 146). Lo icónico no actúa en forma aislada sino "en el interior del flujo semiótico que integra el conjunto cognitivo humano" (Zechetto, 2010: 224). Siguiendo la propuesta teórica-metodológica peirciana, el ícono se divide en tres:

1. Las imágenes como aquellas cualidades simples, "primeridades primeras". Como por ejemplo, una fotografía, un mapa, un cuadro, una melodía.

2. Los diagramas como aquellas que representan las relaciones principalmente diádicas, o consideradas así, de las partes de una cosa mediante relaciones análogas en sus propias partes. Poseen una cualidad semejante en algún punto a su estructura. 
3. Las metáforas como aquellos signos que "representan el carácter representativo de un representamen representando un paralelismo en algo distinto" (Peirce, 1996: 47). Las metáforas representan la cualidad de algún sentido dirigido a alguien. Es un mecanismo semiótico imposible de evitar: no hay cultura ni desarrollo sin metáforas. Son las metáforas las que nos permiten imaginar, abrir el mundo, el conocimiento, la creatividad. Asimismo, el lenguaje cotidiano está plagado de metáforas, desgastadas, devaluadas, instaladas, etc.

Peirce (1996) señala que el único modo de comunicar directamente una idea (o crearla) es mediante un ícono. En este sentido, una "afirmación debe contener un ícono o conjunto de íconos, o bien debe contener signos cuyo significado sea explicable sólo mediante ícono" (Peirce, 1996: 47). De esta manera, el ícono representa una cualidad (su forma, tamaño, peso, forma) del sentimiento. Nos permite poder imaginar una forma, cómo es organizada, ordenada, presentada una cualidad.

Asimismo, podemos entender a lo icónico como una categoría que nos permite fijar creencias y asentar hábitos. En este sentido, las categorías de hábito y creencia nos ayudarán a pensar los procesos aquí trabajados. El hábito es producido por la semiosis, es una regla de conducta entre los signos, una regularidad (nos habituamos a pensar/ actuar de determinada manera). Mientras que la creencia, son reglas de conductas por la cual el sujeto está dispuesto a actuar. Ambos se refieren a la cultura y a la sociedad en la cual se insertan. La creencia y el hábito actúan y operan conjuntamente: "nuestro hábito tiene la misma relación que nuestra acción, nuestra creencia la misma que nuestro hábito, nuestra concepción la misma que nuestra creencia" (Peirce, 1988: 3). La esencia de la creencia es el establecimiento del hábito, que depende de cuándo y cómo nos mueve a actuar: "lo que respecta al cuándo, todo estímulo a la acción se deriva de la percepción; por lo que respecta al cómo, todo propósito de la acción es el de producir un cierto resultado sensible" (Peirce, 1988: 4). La creencia posee tres propiedades: 1) es algo de lo que no nos percatamos; 2) apacigua la irritación de la duda; 3) involucra el asentamiento de una regla de acción, es decir, de un hábito. De esta manera, la esencia de la creencia según Peirce es el asentamiento de un hábito. Las diferentes creencias se distinguen por los diferentes modos de la acción a la que dan lugar (Peirce, 1988: 5).

\section{Cualidades hechas canciones}

Durante nuestra instancia de trabajo de campo (2013-2015) observamos que la puesta en escena del 30 de noviembre coincide con el cierre de actividades anuales. En este contexto -siguiendo el relato de nuestros entrevistados-, el acto pasa a un "segundo plano" debido a la acumulación de actividades y el "desgaste", "cansancio" característico del "fin de año". Esto puede corroborarse en su despliegue organizativo, ya que no se realizan grandes inversiones en decoración en comparación a otros actos escolares, solamente se produce una cartelera principal y se arregla un telón. Asimismo, en estas escuelas se decidió que la entonación de canciones fuera una de las estrategias comunicativas para conmemorar la efeméride. Estas estrategias de comunicación pueden 
estar orientadas a "transformar las prácticas sociales de los actores que adquieren su reconocimiento en un espacio cultural determinado y que se construyen y constituyen atravesados por las determinaciones propias del espacio en que se mueven" (Uranga \& Vargas, 2004: 4). Asimismo, los sistemas de memoria colectiva "han dado lugar al desarrollo de estrategias específicas para construir y controlar la memoria social" (García, 2004: 116). En el empeño por mantenerse (en la memoria) se han producido, constituido, regulado "convenciones, prácticas, rituales, rutinas, en su accionar más o menos central respecto del control y la organización del pasado y el futuro de una formación social, por el recurso, y el control de, la información" (García, 2004: 117). Es decir, han producido y optado por determinadas estrategias de comunicación (oral, escrita, performativa, audiovisual, etc.) para mantener en funcionamiento "engranajes de saber y poder, las máquinas de creer, que también mueven y modelizan el cuerpo social" (García, 2004: 116-117).

En este sentido, debemos destacar el rol de las canciones patrióticas para el asentamiento de hábitos en la conformación nacional de la ciudadanía por parte del Estado y la educación formal. Ya a principios del siglo XX las letras de las canciones que se estudiaban en la escuela entraban en los hogares mediante los niños y niñas escolarizados (Kriger, 2010), fue así que desde en un primer momento sirvieron como un dispositivo importante para "argentinizar":

"Es como si las músicas y danzas funcionaran metonímicamente, haciendo presente un mundo más amplio de sentimientos y significaciones con el que se fueron ligando a través de sus ejecuciones. Lo peculiar es que no sólo re-presentan o evocan esas significaciones y sentimientos sino que tienen un particular poder para hacerlas presentes, activarlas en los sujetos, permitir re-vivirlas" (Citro, 2009: 227)

En su trabajo Citro dialoga con el trabajo de Thomas Turino, etnomusicólogo estadounidense quien investiga la relación del nacionalismo a través música (redacción) y el papel que los lugares de música en la creación de las conexiones que definen una sociedad (Citro, 2009). Este autor trabaja sobre que el poder afectivo de la música y la danza se basan en sus capacidades para actuar como signos indexicales de experiencias y emoción. Siguiendo el programa peirciano, el autor señala que los índices significan a través de la "coocurrencia con su objeto" en una misma situación, pero una vez que las relaciones indexicales han sido establecidas, no es necesaria la copresencia de signo y objeto "ya que el índice puede traer a la mente aquellos objetos con los que estaba ligado en la experiencia e, incluso, ir incorporando otros elementos presentes en cada situación (...) cada ejecución tendría la capacidad de reconectar al sujeto con una serie de afectos y significaciones que ese género provocó en performances anteriores" (Turino, 1999 en Citro, 2009: 227).

En el caso de la efeméride del 30 de noviembre, las canciones no funcionan solamente como espacios para (de) mostrar lo que se ensayó y aprendió en el área de Expresión Artística, sino como signos complejos que pueden instaurar hábitos y 
creencias mediante su (a) puesta como íconos-metáforas. A continuación compartimos el primer ejemplo ${ }^{3}$. La canción es interpretada por Fausto Rizzani, cantautor y músico de reconocida trayectoria en el ámbito del folclore y de la educación debido a su discografía destinada como material didáctico escolar. ${ }^{4}$

\author{
"Banderita de Misiones" \\ "Bandera de Misiones \\ que bellos colores tienes hoy \\ Hermosa banderita \\ adorna mi escuelita tu esplendor \\ La señorita dijo que siempre defendiste mi nación \\ La tierra colorada protege tus colores con honor \\ Bandera de Misiones \\ roja azul y blanca que bella sos \\ Hermosa Banderita \\ quiere saludarte mi corazón"
}

Las canciones proponen una composición/estructura que representan un diagrama en la organización de sus estrofas. Esta cualidad logra ordenar la lectura y estructurar el texto. Propone un inicio, un desarrollo, marca las pausas, los ritmos de la composición musical. Hedman señala ${ }^{5}$ que preexiste una imposibilidad de encuadrar a la canción misionera dentro de un género que contenga elementos que le sean propios, y que la diferencien de otras manifestaciones musicales, incluso de esta misma región (Hedman, 2013). La autora destaca que se comparte un mismo patrón rítmico de la guarania y el chamamé, es decir Paraguay y Corrientes". Asimismo, menciona que en el plano de la forma, las canciones son distintas en la cantidad de versos, estrofas, sílabas, en la métrica.

Si tenemos en cuenta el espacio/tiempo, y la posición de los cuerpos, al momento de la presentación los estudiantes se ubicaron al frente del escenario. Algunos alumnos leen la letra de la canción desde una hoja de papel. Las voces de los estudiantes no se llegaban a percibir debido a que el sonido de la reproducción por los parlantes era muy alto. Los estudiantes ubicados en hileras conformaban también una suerte de diagrama que los organizó en el espacio, de menor a mayor estatura.

3 Como estrategia comunicativa hemos decidido compartir las letras completas dentro del artículo, para que el lector pueda acceder a las mismas con facilidad, y relacionarlas con el análisis.

${ }^{4}$ Fausto Rizzani nació en el sur del país pero hace más de treinta años está radicado en Misiones. Lleva grabadas más de 160 canciones con temáticas relacionadas a Misiones, como ser la fauna, la flora, sus símbolos, etc. Su carrera inició en la década de 1990. Representó a Misiones en el Festival de Cosquín 98', 2000 y 2005. En el festival de Jesús María, cantó en 2003. En Puerto Iguazú -ciudad donde se encontraba la escuela en la cual se entonó esta canción- fue reconocido como Embajador Artístico en el año 1993. Fausto Rizzani es su nombre artístico. Su apellido es Stéfani, hijo del artista misionero Daniel Stéfani, también músico y compositor, quien ha escrito gran parte de las canciones de Fausto. Una de ellas es "Banderita de Misiones" del álbum "Fausto en mi escuela 2" editado en 2009 que está compuesto por quince canciones sobre efemérides patrias argentinas, Andrés Guacurarí, la Bandera de Misiones, entre otros temas. Las letras fueron escritas por su padre, y el disco producido por José Aníbal Giménez. Fuente: http://www.territoriodigital.com/notaimpresa.aspx?c=6128459028842903

5 En nota periodística http://www.territoriodigital.com/nota.aspx?c=6920248171099012 (17/03/2013) 
El objeto de la canción -bandera o banderita de Misiones- es representado mediante una serie de imágenes. Durante su entonación se propone un determinado modo de imaginar sus cualidades. La canción instala (y reitera) los colores que la componen; al mismo tiempo, personifica al objeto (metaforización) al incorporar la práctica del saludo: "quiere saludarte mi corazón".

En este sentido, la canción (mediante el autor y luego su intérprete) posee una intencionalidad: pretende imaginar al objeto mediante determinados enunciados, para la cual ofrece una secuencia de cualidades: sus colores, su belleza, su "valentía", "honor". Incorpora la figura de determinados sujetos reconocibles por los estudiantes: "la seño", en femenino y utilizando una expresión coloquial representa a la docente del grado. Asimismo, el uso del diminutivo quizá busca una suerte de empatía con los niños ya que las canciones del álbum están destinadas a la escuela primaria. "Banderita de Misiones" destaca al objeto como "defensora de mi nación", incorporando a sus intérpretes un sentimiento de pertenencia al objeto.

Desde sus primeros acordes, como ícono-imagen, la canción se instala como un sonido, una melodía que representaría un ritmo "regional", "propio", "local", como en este caso es el chotis ${ }^{6}$. Su melodía podría ser reconocida por los presentes o bien pretender ser situada en la memoria colectiva como "regional", "propia". Si nos referimos a la "música regional" nuevamente se podría iniciar un extenso debate sobre sus significados, disputas, producciones. Aunque dicha discusión no nos llevaría en esta oportunidad a un puerto seguro ${ }^{7}$-ni tampoco es la intención de nuestro textoconsideramos necesario ofrecer algunas referencias.

La música regional puede ser definida como "una variedad de expresiones musicales que se generan, nutren, seleccionan, decantan, crean, difunden y hallan eco en la sensibilidad de la población de un área geográfica interrelacionada histórica y etnoculturalmente" (Perié, 1983: 5). En este sentido, conforma uno de los elementos para dar respuesta a la producción de una identidad común. Perié (1983) advierte que la realidad de la provincia de Misiones nos permite observar el predominio de algunos ritmos sobre otros, pero que sin embargo es imposible determinar puntualmente un ritmo "local", "autóctono". No sin disputas, se destacan distintos ritmos: la galopa, el chotis, la polca, el gualambao, el chamamé, entre otros. Perié menciona que "no hay jueces para determinar el grado o la legitimidad del sentimiento musical. Hay sí propuestas musicales que provienen de distintos sectores-autores, hay mayor o menor

${ }^{6}$ El chotis deriva del término alemán schottisch («escocés»), una danza social centroeuropea. En Argentina, Paraguay, Uruguay, el chotis o schotis fue introducido por los inmigrantes alemanes y polacos asentados a partir de la segunda mitad del siglo XIX en la región litoraleña de los ríos Paraná, Paraguay y Uruguay. Constituye uno de los estilos destacados de lo que en la Argentina se llama música litoraleña.

7 Destacamos la discusión entablada por dos referentes culturales, Ramón Ayala y el Chango Spasiuk, en el marco del Festival del Litoral en el año 2009, con eco no solamente en el ámbito provincial, sino que también en el escenario nacional. La polémica se puede leer en: La Nación http://www.lanacion. com.ar/1199675-musica-del-litoral-rio-polemica-y-terere (15/11/2009); Página 12 http://www.pagina12. com.ar/diario/suplementos/espectaculos/2-16002-2009-11-15.html (14/11/2009). Retomada y ampliada en una edición especial del diario El Territorio en el marco del 60 Aniversario de la Provincialización, http://www.territoriodigital.com/nota.aspx?c=6920248171099012 (17/03/2013). 
estímulo a unos que otros, pero sobre todo hay una selección que hace el cuerpo social" (Perié, 1983: 33). En este sentido, no es nuestro objetivo aquí seleccionar alguna de estas variantes sino colocarlas en escena como mecanismos semióticos-comunicativos que proponen un tipo de memoria en relación con la música como un bien simbólico. Estos ritmos son reconocibles e identificables por la población que con sus similitudes de estructura y sus diferencias configuran la "música regional".

A continuación compartirnos el segundo ejemplo:

\section{"Andresito" Recitado}

Para la historia oficial fuiste siempre un bandolero,

General improvisado de un ejército harapiento; profanador de costumbres, de apellidos y abolengos; usurpador de la tierra, vengador de tus abuelos... Para nosotros, en cambio, tu nombre seguirá siendo

La sagrada Rebeldía de una dignidad sin precio, que se aguanta la pobreza y sobrevive al saqueo... Hijo fiel de tus mayores, peleando por tus derechos...!

\section{Primera Parte}

Aquí donde no hace mucho vivíamos compartiendo la comida y la plegaria, la música y el festejo... ahora estamos enfrentados entre hermanos, casi en cueros; una vez más invadidos y apenas sobreviviendo...

General Guacurarí, que llegás montado en pelo, tu sombra pasa y nos libra de las coyundas del miedo...

Con sólo decir tu nombre vuelve a soñar nuestro pueblo, resucita la esperanza y nos juntamos de nuevo...! 


\section{Estribillo}

Che Comandante Andresito, montonero guaraní, según sea el invasor, sos aguará o jabalí...

Sos tábano bajo el sol y a la sombra, mbariguí... ¡Centinela de la Patria, de Iguazú a Mandisoví! Sos la memoria viviente de Oberá y Mbororé... que lo diga el español, que lo diga el portugués... ¡Sos Dignidad, sos Justicia, sos Patria Grande de pie! Una vez más, por nosotros: ¡volvé,Andresito, volvé!

\section{Recitado}

¡Pueblos libres! ¡Pueblos libres!

Se oye el grito y se oye el eco que desciende por los ríos y va trepando los cerros...

$\mathrm{Y}$ ese grito libertario, como una bandera al viento, va delante de Andresito y está en la boca del pueblo...!

\section{Segunda parte}

De San Borja a Porto Alegre, maniatado en cuero fresco,

te llevaron caminando como antaño a tus abuelos... Te engrillaron los tobillos, pero no tu viejo sueño que, según se rumorea, logró escapar y anda suelto...!

Paisano de San Martín, hijo de Artigas sabemos que tu lanza montonera marca el rumbo verdadero... $\mathrm{Y}$ en las fronteras del alma, junto al río de los sueños, tu sombra sigue de guardia igual que un tigre en acecho...! 
La imagen-diagrama de la canción se estructura en un primer recitado, primera parte, estribillo, segundo recitado, segunda parte y repetición del estribillo. Advertimos la mayor extensión de este texto en comparación con el primero que compartimos. Asimismo, a diferencia del primer ejemplo, la canción tiene como objeto a Andrés Guacurarí y Artigas, no a la Bandera de Misiones. En este sentido, la canción propone a partir de una trama discursiva densa determinadas características, cualidades y relatos que colocan en escena la figura del héroe misionero.

Este tema musical es interpretado por Mario Bofill cantautor correntino dedicado al chamamé y la música litoraleña de gran popularidad en el noreste argentino ${ }^{8}$. La canción pertenece al género musical del "chamamé". No es un dato menor que un chamamecero correntino le cante al héroe local ya que para la "historia oficial" de la provincia de Corrientes, Andresito fue mucho tiempo representado como un "enemigo", "bandolero", como inicia la canción de Bofill". Asimismo, otra discusión se instala es la elección del género musical. Como mencionamos anteriormente, en el ámbito los cantautores y músicos misioneros, no hay unanimidad sobre qué papel ocupa el chamamé como música "local". Antes de 1960 el chamamé, y otras expresiones musicales regionales, fueron consideradas "malas palabras": no eran reproducidas en medios de comunicación, ni en las fiestas populares, barriales. Recién en los años '60 se comienzan a incorporar en los medios de comunicación, la radio y la televisión (hasta en los vecinos países de Paraguay y Brasil). Sin embargo, aunque el chamamé parece “imponerse como proyección incluso, al Paraguay y Brasil -fenómeno de exterpolación cultural en la frontera con pocos antecedentes-, debería apoyarse la difusión de otros ritmos, teniendo en cuenta la incidencia que este medio tiene para el consumo musical" (Perié, 1983: 31). En nuestro caso, tampoco eran ritmos aptos para ser incorporadas como estrategias ni como dispositivos identitarios en la escuela.

Interpretamos que en este caso este tema musical podría ser elegido por varios motivos: su género, su intérprete, pero consideramos fundamentalmente, por su composición temática-estilística debido a que propone determinada imagen sobre la figura de Andresito. Advertimos que debido a la extensión y posibilidades de análisis que nos ofrece la letra de esta canción, consideramos oportuno seleccionar algunos fragmentos más significativos.

\footnotetext{
8 Bofill nació en 1948, ha compuesto más de 200 canciones que han sido interpretadas por los principales cantantes folklóricos del país. En 2001 su obra musical y artística fue declarada de interés provincial en Misiones por la Cámara de Representantes (C.R./D.283-2.001/2). La letra de la canción "Andresito" es de Julián Zini, la música de Mario Bofill, y el recitado es interpretado por Juan Carlos Jensen. Pertenece al disco "Desde el fondo del baúl" (2001) producido por "Abraham Helu" en la ciudad de Corrientes. Entre su repertorio más reconocido se encuentran "Requecho", "Conjunto Pena y Olvido", "Estudiante del interior", "Viva la Pepa", "Oh che gente cuera", "Cantalicio vendió su acordeón", canción que le mereció el premio a canción inédita en el Festival Nacional del Chamamé en 1988.

9 Son de larga data las disputas por la figura de Andresito en la provincia de Corrientes. Para profundizar sobre esta temática, se puede consultar: Alcaráz, 2014; Cantero, 2014; Machón \& Cantero, 2008, 2010; en notas en medios digitales: "Andresito es historia fabricada desde arriba": http://www.corrienteschamame. com.ar/nuevo/vernota.asp?id_noticia=1506\#.VzosPv197IU (20/03/2012); o el documental "Buscando al Comandante Andresito" (2013) disponible en: https://www.youtube.com/watch?v=gXtT968p7V0
} 
En el primer recitado, el autor instala una diferencia que divide en dos bloques los sentidos que se poseen sobre Andresito. Por un lado, menciona a la "historia oficial" (correntina, aristocrática, de elite) que lo presenta como un "bandolero", "profanador de costumbres", "de apellidos", "usurpador de tierras". En este caso la figura del héroe es contrarrestada por esta versión como un persona negativo para ese relato histórico. Por otro lado, Andresito es representado como rebelde, digno, pobre (como su pueblo), luchador por los derechos. En este caso, su figura histórica es instalada como un representante, un héroe. Asimismo, mediante el pronombre "nosotros" el autor toma posición y se distancia con la otra versión. En el caso de la puesta en la escena escolar, nos lleva a interpretar también una suerte de adscripción institucional a este segundo bloque.

En la primera parte, el autor comienza a narrar una historia, la cual podría entrar en diálogo con los cuentos que se relatan en los actos del 25 de mayo, haciendo uso de una similar estrategia: "aquí donde no hace mucho". Propone un cronotopos compartido por los intérpretes de la canción, que coinciden en un mismo tiempo y lugar. Asimismo, destaca como elementos "nuestros" a la "comida", "música", "plegaria", "festejo". En este sentido, no solamente se representan las cualidades para pensar una fiesta/celebración, sino también espacios fuertemente ligados a la liturgia religiosa. Se agregan más sentidos a la idea de comunidad cuando se canta "¡Con sólo decir tu nombre // vuelve a soñar nuestro pueblo, // resucita la esperanza // y nos juntamos de nuevo...!" El nombre "Andresito" despierta una complejidad de sentidos que la canción propone imaginar: mediante su nombre puede hacer "soñar" al pueblo y volver a reunirlo. Es interesante esta metáfora debido a que los restos de Andrés Guacurarí nunca han sido encontrados, esto sumado a los pocos documentos que hacen referencia a su nacimiento. $\mathrm{Su}$ figura envuelve en parte misterio en relación a su nacimiento y muerte, sin lograr ser esclarecidos hasta la actualidad. Por ejemplo, con respecto al año de nacimiento se discuten las fechas que van desde 1778 hasta 1790. En cuanto al lugar de su nacimiento:

"los conflictos fronterizos y la destrucción consiguiente de mucha documentación (incluyendo numerosos libros parroquiales de los pueblos) hace que no se pueda saber con precisión dónde y cuándo nació. Es probable que lo haya hecho en el pueblo de San Borga, aunque algunos historiadores sostienen que lo hizo en Santo Tomé. Tampoco se puede fijar la fecha; posiblemente vino al mundo un 30 de Noviembre, ya que, por su nombre de pila, resulta probable que lo haya hecho en el día de San Andrés" (Machón \& Cantero, 2010: 66). ${ }^{10}$

En este sentido, solamente con su nombre logra la fuerza para "juntar" al pueblo, sin necesidad de un espacio físico donde poder recordarlo, sí de un acto celebratorio.

${ }^{10}$ Por otra parte, la situación que hace referencia a su muerte entra en dialogo con la instalación de un cenotafio junto al monumento de Andresito en la costanera de Posadas, Misiones. Nota titulada "Habrá una tumba vacía bajo el monumento a Andresito" (2/08/2013), disponible en http://www.territoriodigital. com/nota3.aspx?c=8734279607083031 
Traverso menciona que las sociedades construyeron una memoria colectiva en cualquier tiempo y lugar, conservándola mediante ritos y ceremonias:

"En occidente, tradicionalmente, "los ritos y los monumentos funerarios celebraban la transcendencia cristiana -la muerte como pasaje hacia el más allá- $\mathrm{y}$, al mismo tiempo, reafirmaba las jerarquías sociales de aquí abajo. En la modernidad las prácticas conmemorativas se transforman (...) A partir del siglo XIX, los monumentos conmemorativos consagran valores laicos (la patria), defienden principios éticos (el bien) y políticos (la libertad), o celebran acontecimientos fundacionales (guerras, revoluciones). Empiezan a convertirse en símbolos de un sentimiento nacional vivido como una religión civil"'" (Traverso, 2011: 16-17).

En el estribillo (que se repite al final de la canción), el autor genera una proximidad con el personaje al llamarlo "Che", aunque lo posiciona con un rango mayor al referirse a su figura como "Comandante". En la canción también se hace mención de la toponimia de la región, su flora y la fauna, como por ejemplo al aguará (del guaraní, zorro), tábano (insecto hematófago), mbariguí (jején, insecto de la familia de los mosquitos). Con la frase, "Sos tábano bajo el sol y a la sombra, mbariguí...", recurriendo a la fauna de la región, hace referencia a la idea de un personaje que "molesta" y-aunque pequeño (de estatura, de ahí el uso del diminutivo en su nombre de pila)- hace notar su presencia. Asimismo, posiciona la figura de Andresito y su causa a una "Patria Grande" considerándolo también como "Centinela de la Patria". En este sentido, la causa de Andresito se inscribe en procesos más complejos y significativos para la región y lo ubica con un rol protagónico en los discursos nacionales, hijo de José Artigas, "paisano" de San Martín. Andresito es "memoria viviente" ya que su lucha continua vigente aún en el "pueblo" que hoy le canta y se reúne a recordarlo. Por su parte, su memoria está en constante construcción y movimiento teniendo en cuenta los procesos que hemos mencionado. Andresito es una figura que se instala hace pocas décadas en la "historia oficial" de la provincia. Aunque la Bandera (sus formas, sus colores, sus cualidades) no son mencionadas en la canción, el autor menciona que "el grito libertario" como la bandera que lleva Andresito, y que los colores del estandarte misiones tienen como objetivo reivindicar.

El estribillo -que se repite al final de la canción- culmina con la frase: "Una vez más, por nosotros: ¡volvé, Andresito, volvé”. A partir de los movimientos que toma la semiosis, consideramos que estas palabras parecerían estar íntimamente relacionadas con un discurso de redención cristiano, en el cual el salvador "Jesucristo" volvería por sus fieles a salvarlos. Aquí, Andresito, como héroe, ocuparía esta misma función.

En el segundo recitado, se vuelve a instalar la figura de un estandarte, como símbolo que desciende de la toponimia misionera. El pedido solicita la liberación de los pueblos, causa que fue encomendada a Andresito. Finalmente, en la segunda parte, relata el 
recorrido de Andresito una vez tomado prisionero. El autor menciona cómo a pesar de esta privación, su lucha e ideales seguirían intactos -hoy en la memoria de un pueblo-. En esta sección también es considerado un "paisano de San Martín”, por la ubicación geográfica en la cual se considera que nació Andresito, al mismo tiempo, que lo ubica como igual en causa y luchas con quien es considerado el "Padre de la Patria" en Argentina.

Asimismo, el interprete hace referencia también a su "lanza montonera", como objeto con el cual marca "el rumbo verdadero". Destacamos en este contexto la producción de determinados dispositivos simbólico-indentitarios como la "lanza de Andresito" incorporada en 2015 por el Estado provincial. La figura del Gobernador marcaría "el rumbo" de la provincia mediante la "lanza de Andresito". La misma fue confeccionada por el reconocido orfebre Carlos Daniel Pallarols ${ }^{11}$. El artista señala que "esta lanza recuerda la fuerza con la que él luchó por su tierra y con la que defendió sus ideales y su identidad. Símbolo de rectitud, justicia y heroísmo". El denominado bastón de mando "representa la voluntad de lucha de Andresito y sus indios, y fue realizada en homenaje al pensador y creador del Centro del Conocimiento, Ing. Carlos Rovira" según expreso el artista. La pieza está construida en plata 921 Argentina, el escudo de Misiones en oro 18 y la madera es anyico colorado, nativa de Misiones. El pasado 10 de diciembre de 2015, cuando el actual gobernador de la provincia de Misiones, Hugo Pasalacqua asume el mando, se realizó por primera vez el paso simbólico mediante "la lanza de Andresito" que consistió en que el gobernador saliente transfiere la titularidad del cargo ejecutivo provincial al gobernador entrante. Con la "lanza de Andresito", Passalacqua juró como gobernador de Misiones. Un medio local describe que "alzó la lanza que simboliza el bastón de mando del cacique convertido en prócer, como símbolo de la defensa de los intereses misioneros."12 En su primer discurso, el gobernador destacó que en los despachos oficiales ya no habrá más la foto del gobernador, sino una imagen de Andresito, porque "nosotros somos pájaros de paso (...) El poder está en la gente y eso nos llena. Soñando con una sociedad más unida y en el marco de respeto. Viva Misiones, viva la Patria".

Además del análisis de la canción, podemos mencionar el despliegue escénico que acompañó el canto. Durante esta performance los estudiantes recitaron y cantaron sin ninguna "ayuda memoria". Esta situación nos llamó la atención por la extensión del texto, y por el modo de "poner el cuerpo" y la voz durante la puesta en escena. Se escuchaba claro y fuerte el recitado y el canto de los niños. Cuando finalizó, un adulto del público grita “¡Bravo!”, a lo que continúan fuertes aplausos. Pudimos observar (sentir, percibir, interpretar) un sentimiento de emoción en la voz de los niños y del

${ }^{11}$ Carlos Daniel Pallarols es $7^{\circ}$ generación de orfebres de Argentina, tiene una gran trayectoria reconocida en el país y el exterior, y desde hace 32 años realiza los bastones presidenciales de mando.

${ }^{12}$ Un diario local narra de manera emotiva dicho traspaso: "La ceremonia de traspaso de mando fue emocionante, con la bendición de los caciques guaraníes y su ceremonia Pitangua, que bendice el nacimiento, en este caso, del nuevo Gobierno. Fuera, en la plaza seca de la Legislatura, otro grupo de guaraníes bailaban el rito Tangará, que se utiliza cuando una comunidad recibe visita de otra aldea." Nota completa disponible en: http://misionesonline.net/2015/12/10/hoy-a-las-1130-tomaran-juramentoel-gobernador-y-vicegobernador-electo-de-misiones/ 
público presente. La docente, luego de los aplausos finales, destaca la participación de los estudiantes de séptimo año, quienes culminan sus estudios en el presente ciclo lectivo, señala: “estos niños merecen más aplausos (continuaron los aplausos con más fuerza) no solamente porque son de séptimo y se van, sino porque ayer estuvieron con su despedida de séptimo y a pesar de ello estuvieron todos hoy aquí presentes para acompañar a la maestra que prepararon el número. Muchísimas gracias" (continúan los aplausos). De esta manera, la representación posee un valor lógico, ético y estético, en un sentido peirciano: la puesta en escena en sí (lógico); el asistir al acto pese a otras actividades (ético); la imagen de estos niños que este año se despiden de la educación primaria, aún interesados en las actividades escolares (estético).

\section{La metáfora "oficial"}

Además de las canciones que los docentes seleccionan para recordar a determinado símbolo (héroe, bandera, momento histórico) co-existen otras que se instalan en la escena de los actos patrios escolares como "obligatorias", "oficiales". Consideramos que éstas se encuentran enfocadas a instalar y convertirse en hábitos desde la implementación y aplicación de una creencia. Este es el caso de la Canción Oficial de la provincia de Misiones, denominada "Misionerita", que se entona en todos los actos escolares (exceptuando el 20 de junio, "Día de la Bandera Nacional Argentina") durante el momento ceremonial del formato.

La misma se reglamenta primero por Decreto en el año 2000, tomando fuerza de Ley en 2002 (Ley VI N97, antes Ley N³910/2002). El artículo 2 dicta que "será entonada obligatoriamente después del Himno Nacional en todos los actos oficiales y escolares que se realicen en establecimientos dependientes del Gobierno de la Provincia". Asimismo, en el artículo 3 menciona que "será obligatorio su aprendizaje y difusión en toda la comunidad educativa de la Provincia, a la que se proveerá de la letra, grabaciones y partituras musicales pertinentes". Por otra parte, cuando se entona esta canción -al igual que el Himno Nacional- los asistentes se mantienen de pie como signo que representaría "respeto", "solemnidad", jerarquía, aunque no se encuentre reglamentada en algún documento oficial; y cuando finaliza, se realizan aplausos sin un pedido explícito del docente presentador.

Consideramos que su institucionalización como "canción oficial" forma parte de las estrategias comunicativas por parte del Estado provincial para la conformación de una serie de dispositivos identitarios provinciales, en los que también se destacan la figura de Andrés Guacurarí y Artigas y la Bandera de Misiones. Como menciona el proyecto de Ley que lo impulsa: “con la incorporación de la canción 'Misionerita' como canción oficial de la provincia de Misiones se completa la trilogía de símbolos (a los que se suma el escudo y bandera) que identifican muy especialmente a la provincia en el contexto de las provincias argentinas y además en toda esta región de América del Sur". Desde el Estado provincial se pretende la producción de una batería de símbolos que buscan representar a la provincia. En este sentido, el proyecto continúa y destaca que "no cabe dudas que cada vez que se entonen las estrofas de 'Misionerita' en los actos 
escolares o en los actos oficiales cada ciudadano misionero manifestará con orgullo su identidad y la proyectará más allá de los tiempos"13. Compartimos a continuación la letra de la canción "Misionerita", su autor es Lucas Braulio Areco ${ }^{14}$.

\author{
"Misionerita" \\ Bajo un hermoso y dulce cielo guaraní, \\ reluce eterna la aurora feliz, \\ en la esmeralda de tu selva como el mar, \\ hay cien caminos de mágico rubí. \\ Bajan las aguas del gran Río elemental, \\ sobre tu flanco, maduro al sol, \\ carne vibrante el corazón de la espesura \\ es un misterio impenetrable, \\ en la noche azul. \\ Estribillo \\ Misionerita, \\ un corazón canta \\ endecha tierna de rendido amor, \\ en el homenaje a tu heroica tierra \\ dejo el acento de mi corazón; \\ tiembla en el pecho \\ de tu voz el canto, \\ con voz de guitarra, la dulce ilusión, \\ es hechizo que regalas a los vientos \\ que te arrullan con ternura, \\ en tu esplendor.
}

Se estima que "Misionerita" fue compuesta entre 1943 y 1958 y seleccionada como "canción oficial" en el año 2000 mediante un concurso "cuyas bases y condiciones excluyeron deliberadamente la participación de composiciones rotuladas como chamamé", dicta el sitio web que reúne la obra de Areco. Dicha memoria ejercida (Ricoeur, 1999) no

\footnotetext{
${ }^{13}$ Proyecto de Ley disponible en http://www.diputadosmisiones.gov.ar/expedientes/docs/2004/proyectos/ PR4566.pdf

${ }^{14}$ Areco nació en 1915 en Santo Tomé (Corrientes) y en 1994 falleció en la ciudad de Posadas. Además de músico y compositor fue artista plástico (pintura, dibujo, grabado, talla, escultura, etc.), escritor (poemas, cuentos breves, textos historiográficos y funcionario público en Misiones durante las décadas de 1960 y 1970. "Su obra se encuentra hoy diseminada en colecciones públicas y privadas de América y de Europa. Igual en Misiones: una porción está dispersa en colecciones privadas y otra en exhibición pública como bien patrimonial del Estado provincial" "Se vinculó tempranamente a la Junta de Estudios Históricos de Misiones (1939), publicando varios relatos históricos en los Boletines de esa institución. Supeditado al objetivo político de reivindicación provincialista que perseguía la Junta". Las referencias que citamos de Areco son tomadas de un blog confeccionado por su familia. Este sitio web se presenta "destinado a especialistas, estudiantes y público en general, este espacio (sin vinculación gubernamental y sin fines de lucro) tiene por fin difundir en forma libre y gratuita la obra de Lucas Braulio Areco. Disponible para consultas: http://lucasbraulioareco.blogspot.com.ar/
} 
fue ajena a las discusiones en torno a selección de determinado ritmo, artista, canción por sobre otros también destacados en la provincia. En este sentido, el ritmo seleccionado para la canción oficial es la galopa misionera, género musical y de danza ${ }^{15}$.

La composición se destaca por su riqueza; se puede contemplar un complejo entramado de metáforas que hablan de su objeto "Misionerita". La rica trama de la poesía de Areco promueve imaginar un ser que busca existir. La "misionerita" se presenta en femenino y en diminutivo. Abundan los adjetivos calificativos para nombrar el paisaje, la tierra, el río, el cielo: hermoso, dulce, eterno, feliz, mágico, de color esmeralda.

Se destaca la idea de "misterio", como un espacio/tiempo que no puede ser del todo comprendido, explicado, abarcado: "carne vibrante el corazón de la espesura // es un misterio impenetrable, //en la noche azul". Se resalta aquí su composición geográfica. Otra de las metáforas que se construye es la idea sobre lo "heroico": tierra heroica, esplendorosa, conjuga un espacio/tiempo "relevante", "destacable" en donde han sucedido hechos "importantes". En este contexto, interpretamos que "Misionerita" representa la tierra (el suelo, el territorio) que posee determinadas características (dulzura, ilusión, amor) y que es correspondido por quién lo canta, quien "ofrece su corazón" que puede evocar una serenata, si se repara en el adjetivo femenino: diminutivo de Misiones y femenino como provincia (objeto de devoción -amor -respeto).

En relación -además de la composición del tema musical- son interesantes las presentaciones que los docentes realizan de la canción mediante las denominadas "glosas". Compartimos a continuación algunas de ellas:

\section{Acto del 30 de noviembre, Escuela $N^{\circ} 2$}

Docente presentador: La dulce ilusión que se extiende bajo un manto guaraní también es canción. No con menos entusiasmo entonamos Misionerita, nuestra canción oficial.

\section{Acto del 30 de noviembre, Escuela $N^{\circ} 1$}

Docente presentadora: Con igual emoción cantamos las estrofas de nuestra canción oficial de la provincia de Misiones, "Misionerita".

"Misionerita" es presentada como la canción que simboliza a la totalidad del pueblo misionero. Asimismo, mediante el uso de las frases "no con menos entusiasmo" o "con igual emoción", se sienta posición de que esta canción debe ser interpretada, "querida", "valorada", de la misma manera que el Himno Nacional Argentino. Ambas canciones patrióticas, aunque distantes entre sí en los tiempos de su aplicación, se presentan como ahistóricas, baluartes de lo que somos como comunidad (argentina, misionera). Al mismo tiempo estas frases se pueden leer en clave de disputa, como un llamado de atención a los "Grandes Relatos de la Nación" que pareciera nuclear en un puñado de dispositivos y símbolos la totalidad de los sentidos de lo nacional. La Canción Oficial de la Provincia de Misiones aparece hoy como emergente pero que sin

\footnotetext{
${ }^{15}$ Este estilo proviene del galop, una expresión llegada desde Francia. Es una danza animada, introducida a finales de los años 1820 a la sociedad parisina por la duquesa de Berry y popular en Viena, Berlín y Londres.
} 
embargo se instala como dominante. De esta manera, en el discurso "oficial" (escolar) la canción "Misionerita" se posiciona como una canción que "también ha estado siempre".

Durante nuestro trabajo de campo fue notable cómo se entona con mayor fuerza (en clave prosódica, kinésica) la canción "Misionerita" que el "Himno Nacional", y cómo en varias oportunidades es necesario la advertencia de los docentes para que los chicos demuestren "respeto" mediante determinada postura del cuerpo. En palabras de Anderson "por triviales que sean las palabras y mediocres las tonadas, hay en esta canción una experiencia de simultaneidad. Precisamente en tales momentos, personas del todo desconocidas entre sí pronuncian los mismos versos con la misma melodía" (Anderson, 1983: 204), y hasta se bailan-agregamos- las mismas danzas.

\section{Consideraciones finales}

En el presente artículo nos preguntamos e intentamos comenzar a comprender (dilucidad, armar) algunas estrategias icónicas en la conmemoración de la efeméride del "30 de noviembre". Pudimos comenzar a reflexionar y analizar distintos mecanismos semióticos-comunicativos mediante los cuales determinados sentidos y significaciones se van haciendo cuerpo/hábito y creencias en la conmemoración de una efeméride. Para ello, colocamos en escena tres canciones que conceptualizamos como íconos para imaginar determinados sentidos sobre Misiones. Esto nos permitió abrir al mundo un modo de ser (que busca fijar creencias, hábitos), signos complejos que pueden instaurar hábitos y creencias mediante su (a) puesta como íconos-metáforas. Por un lado, una canción considerada "oficial", "obligatoria", y por otro lado, dos que fueron seleccionadas por docentes de las organizaciones escolares que conformaron nuestro trabajo de campo con motivo de recordar a determinado "símbolo" (héroe, bandera, momento histórico). En todos estos casos el objeto de las canciones hacen referencia a la efeméride: Andrés Guacurarí y Artigas o la Bandera de Misiones. En este sentido, las canciones proponen, a partir de determinadas características, cualidades y relatos, poner en escena estos objetos.

Observamos cómo las canciones proponen una composición/estructura que representan un diagrama en la organización de sus estrofas. Esta cualidad logra ordenar la lectura y estructurar el texto: propone un inicio, un desarrollo, marca las pausas, los ritmos de la composición musical. La ubicación de los estudiantes durante su presentación conforma también una suerte de diagrama que los organizó en el espacio.

Asimismo, mediante la puesta en escena de las canciones (obligatorias, seleccionadas) se logra representar determinadas cualidades del objeto. Proponen imaginar tamaños, paisajes, diseños, colores, personajes. Nos ofrecen una lectura sobre los sentidos de la Bandera (la elección de sus colores, la justificación como emblema, su "belleza) o del prócer misionero (los valores del personaje, su trayectoria de vida). Todos estos sentidos se realizan mediante una lectura desde el presente, sobre los sentidos que hoy se quieren representar e interpretar. 
En el caso de la canción oficial de la provincia de Misiones, denominada "Misionerita", es presentada como la canción que simboliza a la totalidad del pueblo misionero y aparece hoy como emergente pero que sin embargo se instala como dominante. Junto con el Himno Nacional Argentino, ambas canciones patrióticas -aunque distantes entre sí en los tiempos de su aplicación- se presentan como a-históricas, "baluartes" de sentidos de la comunidad (argentina, misionera). Consideramos que aunque logren convivir ambos, cada uno con sus tiempos pautados, "Misionerita" busca instalarse en la memoria pública, social, de los misioneros.

Mediante las canciones los autores y sus intérpretes toman posición y seleccionan determinadas cualidades sobre el objeto al que cantan. Esta puesta en escena de la memoria no se da sin disputas, revisiones, construcciones, producciones y debates, dado que hasta los ritmos que se eligen para representar al objeto se encuentran en tensión con otros ritmos, los cuales pujan por un lugar en la memoria. Desde sus primeros acordes, las canciones como íconos-imágenes se instala como un sonido, una melodía que representaría un ritmo "regional" "propio", "local": chotis, chamamé, etc. Sus melodías podrían ser reconocidas por los presentes o bien pretender ser situada en la memoria colectiva como "regional", "propia".

\section{Referencias bibliográficas}

Alcaráz, J. 2014. "La "Provincia Argentina de Misiones en la Historia de la Nación Argentina". En: N. Oviedo \& J. Alcaráz. (comps.) Misiones. 60 Aniversario de la provincialización. Posadas: Editorial de la Universidad Nacional de Misiones, pp. 79-98.

Anderson, B. 1983. Comunidades imaginadas. Reflexiones sobre el origen y la difusión del nacionalismo. México: Fondo de Cultura Económico.

Aranciaga, I. 2004. "Representaciones de la nación en la Patagonia. ¿Qué es ser miembro de una nación en crisis?”. En: E. Vernik. (comp.). Qué es una nación. La pregunta de Renán revisada. Buenos Aires, Prometeo, pp. 97-111.

Areces, N. 2008. "Posibilidades y limitaciones de la cuestión regional. Entre la historia colonial y nacional.” En: S. Bandieri; G. Blanco, Graciela \& M. Blanco (coords.) Las escalas de la historia comparada. Tomo 2: empresas y empresarios. La cuestión regional. Buenos Aires: Miño y Dávila, pp. 247-270.

Augé, M. 1995. Hacia una antropología de los mundos contemporáneos. Barcelona: Gedisa. Bajtín, M. 1982. Estética de la creación verbal, México, Siglo XXI.

Batticuore, G. \& Gayol, S. 2011. "Miradas a la cultura argentina: 1810-1910-2010". En: Batticuore, G. \& Gayol, S. (comps.) Tres momentos de la cultura argentina: 1810 - 1910 - 2010. Buenos Aires, Prometeo, pp. 9-24.

Bertoni, L. 2001. Patriotas, cosmopolitas y nacionalistas. La construcción de la nacionalidad argentina a fines del siglo XIX. Primera edición, Segunda Reimpresión. Buenos Aires, Fondo de Cultura Económico.

Blázquez, G. 2011. Los actos escolares. La invención de la patria en la escuela. Buenos Aires, Miño y Dávila. 
Blázquez, G. 2012. Los actos escolares. El discurso nacionalizante en la vida escolar. Buenos Aires, Miño y Dávila.

Caggiano, S. 2007. "Racismos y nación ante la inmigración. La percepción del "otro", la cultura y los derechos en la producción de las fronteras" en Oficios Terrestres. N.19, pp.10-23.

Caggiano, S. 2013. "El ordenamiento y la diseminación. Imágenes y categorías en el Archivo General de la Nación”. En: Oficios Terrestres. N.29, pp.1-29.

Camblong, A. 2009. "Habitar la frontera" en Fronteras. DeSignis. Núm. 13. Buenos Aires, La Crujía, pp. 125-133.

Camblong, A. 2014. Habitar las fronteras. Posadas, Editorial Universitaria de la Universidad Nacional de Misiones.

Cantero, O. 2014. "La Provincia Guaranítica de Misiones: una propuesta de periodización." En: N. Oviedo \& J.Alcaráz. (comps.) Misiones. 60Aniversario de la provincialización. Posadas: Editorial de la Universidad Nacional de Misiones, pp.11-32.

Carretero, M. 2007. Documentos de identidad. La construcción de la memoria histórica en un mundo global. Buenos Aires: Paidós.

Carretero, M. \& Kriger, M. 2010. "Enseñanza de la historia e identidad nacional a través de las efemérides escolares”. En: Carretero, Mario y Castorina, José (comp.) La construcción del conocimiento histórico. Enseñanza, narración e identidades. Buenos Aires, Paidós. Cap. II.

Carretero, M., Rosa, A. y González, M. (comps.) 2006. Enseñanza de la historia y memoria colectiva. Buenos Aires, Paidós.

Carrión, F. 2012. "Conmemoraciones, construcciones, disputas" en Gutman, M. \& Molinos, R. (eds.). Construir bicentenarios latinoamericanos en la era de la globalización. Buenos Aires, Infinito, pp.57-70.

Citro, S. 2009. Cuerpos significantes. Travesías de una etnografía dialéctica. Buenos Aires: Biblos.

Coviello, A. (Coord.) 2014. Términos fundamentales de la semiótica. San Miguel de Tucumán: Universidad Nacional de Tucumán.

De Haro, G. 2005. "La educación de Misiones, un conflicto abierto entre las pedagogías impuestas, adaptadas y las autónomas-críticas" en Revista Estudios Regionales, Año 12, núm 31, noviembre. Posadas: Secretaría de Investigación y Postgrado de la Facultad de Humanidades y Ciencias Sociales de la Universidad Nacional de Misiones, pp. 45-53.

Díaz, R. 2009. "Los actos escolares. Entre la representación y la identidad". En: Revista El Monitor de la educación. Número 21, Quinta temporada. Junio 2009. Ministerio de Educación de la Nación, CABA, pp. 38-40.

Dussel, I. 2007. "El guardapolvo blanco". En: Revista El Monitor de la Educación. No 12, Mayo-Julio, Ministerio de Educación de la Nación, p. 42-44. Disponible: http://www.me.gov.ar/monitor/nro12/museo.htm.

Dussel, I. y Southwell, M. 2009. "Los rituales escolares: pasado y presente de una práctica colectiva” en Revista El Monitor de la educación. Número 21, Quinta temporada, 
Junio 2009. Ministerio de Educación de la Nación, CABA. Disponible: http:// www.me.gov.ar/monitor/nro5/dossier1.htm

Escudé, C. 1990. El fracaso del proyecto argentino. Educación e ideología. Buenos Aires, Instituto Torcuato Di Tella/CONICET.

Finol, J. 2002. "Cuerpo y rito: la estructura del gesto en ceremonias públicas." En: M. Rector (coord.) DeSignis 3. Los gestos. Sentidos y Prácticas, Barcelona, Gedisa, pp. 81-90.

Finol, J. 2006. "Rito, espacio y poder en la vida cotidiana". En: Finol, J. E. (coord.) DeSignis. 9. Mitos y Ritos en las Sociedades Contemporáneas, Barcelona, Gedisa, pp. 33-43.

García, M. 1999. "La narración de la historia nacional en el texto escolar de Argentina", Madrid, Facultad de Ciencias de la Información de la Universidad Complutense de Madrid, tesis de doctorado.

García, M. 2004. Narración. Semiosis/Memoria. Posadas, Editorial Universitaria de Misiones.

García, M. 2012. Exploraciones discursivas. Posadas: Ediciones del autor. ISBN 978987-33-2337.

Goldman, N. 2009. ¡El pueblo quiere saber de qué se trata! Historia oculta de la Revolución de Mayo. Buenos Aires, Sudamericana.

Grimson, A. 2002. El otro lado del río. Periodistas, Nación y Mercosur en la frontera. Buenos Aires, Eudeba.

Gutman, M. 2012. Planes y expectativas de conmemoración (2000-2009) En: Margarita

Gutman \& Rita Molinos (eds.) Construir bicentenarios latinoamericanos en la era de la globalización. Buenos Aires: Infinito (pp.37-56).

Halbwachs, M. 1950/2011. La memoria colectiva, Buenos Aires: Miño \& Dávila.

Jaquet, H. 2005. Combates por la invención de Misiones. Posadas: Editorial Universitaria.

Kriger, M. 2010. Jóvenes de escarapelas tomar. Escolaridad, comprensión histórica y formación política en la Argentina contemporánea. Primera Edición. Universidad Nacional de la Plata, Facultad de Periodismo y Comunicación Social; Observatorio de Jóvenes, Comunicación y Medios. La Plata, 2010.

Lotman, I. 1996. La Semiosfera I Semiótica de la cultura y del texto. Madrid, Disiderio Navarro. Lotman, I. 1998. La Semiosfera II Semiótica de la cultura, del texto, de la conducta y del espacio. Madrid, Disiderio Navarro.

Machón, J. y Cantero, D. 2008. 1815-1821. Misiones. Provincia Federal. Posadas: Editorial de la Universidad Nacional de Misiones.

Machón, J. \& Cantero, D. 2010. “Andrés Artigas y la Provincia Federal de Misiones.” En Miradas históricas sobre Misiones en el Bicentenario, Gobierno de la provincia de Misiones y la Junta de Estudios Históricos de Misiones. Posadas: Junta de Estudios Históricos de Misiones, pp. 62-93.

Magli, P. 2002. "Para una semiótica del lenguaje gestual". En M. Rector (coord.) DeSignis 3. Los gestos. Sentidos y Prácticas. Octubre 2002. Barcelona: Gedisa. (pp. 37-51).

Mancuso, H. 2010. De lo decible. Entre semiótica y filosofía: Peirce, Gramci, Wittgenstein. Buenos Aires, Editorial SB.

Martín-Barbero, J. 2002. Oficio del cartógrafo. Travesías latinoamericanas de la comunicación en la cultura. Chile: Fondo de Cultura Económica. 
Middleton, D \& Derek, E. (comps.) 1992. Memoria compartida. La naturaleza social del recuerdo y del olvido. Barcelona, Paidós.

Milstein, D. \& Mendes, H. 1999. La escuela en el cuerpo. Estudios sobre el orden escolar y la construcción social de los alumnos en las escuelas primarias. Madrid, Miño y Dávila.

Nora, P. 2008. Les lieux de mémoire. Traducción por Laura Masello. Montevideo: Ediciones Trilce.

Ocoró Loango, A. 2009. "La representación de la negritud en los actos escolares del 25 de Mayo" en Revista El Monitor de la educación, Número 21, Quinta temporada, Ministerio de Educación de la Nación, CABA, pp. 36-37.

Ocoró Loango, A. 2010. Afroargentinidad y memoria histórica: La negritud en los actos escolares del 25 de Mayo. Buenos Aires, Facultad Latinoamericana de Ciencias Sociales, tesis de maestría.

Ortemberg, P. 2013. "Sentidos e historia de las fiestas patrias: una introducción". En: Ortemberg, Pablo (dir.), El origen de las fiestas patrias. Hispanoamérica en la era de las independencias. Rosario, Prohistoria, pp. 11-26.

Peirce, C.1988. "La fijación de la creencia." Traducción castellana y notas de José Vericat. (Recuperado en marzo de 2016 en http://www.unav.es/gep/FixationBelief.html).

Peirce, C. 1996. La ciencia de la semiótica. Buenos Aires: Nueva Visión.

Perié, A. 1983. "Música regional. Análisis socio-cultural". Posadas, Centro de Investigaciones histórico-culturales de la Facultad de Humanidades y Ciencias Sociales de la Universidad Nacional de Misiones.

Ricoeur, P. 1999. La lectura del tiempo pasado: memoria y olvido. Primera reimpresión. Madrid: Arrecife.

Rodríguez, M. I. 2011. Todo está guardado en la memoria. El acto escolar como formato comunicativo que reactualiza la memoria colectiva nacional. Tesis de Licenciatura en Comunicación Social. Facultad de Humanidades y Ciencias Sociales de la Universidad Nacional de Misiones. Septiembre, 2011.

Rodríguez, M. I. 2015. El acto escolar como formato comunicativo. Todo está guardado en la memoria. Posadas: Editorial Universitaria de la Universidad Nacional de Misiones.

Rodríguez, M. I. 2016. "Los actos de memoria: un estudio sobre efemérides y actos patrios en escuelas de la provincia de Misiones (Argentina)." Tesis de Doctorado. Doctorado en Comunicación de la Facultad de Periodismo y Comunicación Social de la Universidad Nacional de Misiones. Octubre, 2016.

Romero, L. (coord.) 2004. La Argentina en la escuela. La idea de nación en los textos escolares. Buenos Aires, Siglo XXI.

Torres, S. 2004. "La Patagonia en el proceso de construcción de la nación argentina". En: Vernik, E. (comp.). Qué es una nación. La pregunta de Renán revisada. Buenos Aires, Prometeo, pp. 83-96.

Traverso, E. 2011. El pasado, instrucciones de uso. Buenos Aires: Prometeo.

Uranga, W. \& Vargas, T. 2004. "Lo público: lugar de la comunicación. Hacia la redefinición de procesos y estrategias comunicaciones." Disponible: http://www. washingtonuranga.com.ar/images/propios/13_lo_publico.pdf. 
Vain, P. 1997. Los rituales escolares y las prácticas educativas. Posadas, Editorial Universitaria. Zecchetto, V. 2012. "La teoría semiótica". En: V. Zecchetto. (Coord.) Seis semiólogos en busca de lector. Buenos Aires: La Crujía, pp. 47-78

\section{Sitios webs}

El territorio Digital:

http://www.territoriodigital.com/nota.aspx?c=6920248171099012

http://www.territoriodigital.com/nota3.aspx?c=8734279607083031

Misiones On-Line:

http://misionesonline.net/2015/12/10/hoy-a-las-1130-tomaran-juramento-elgobernador-y-vicegobernador-electo-de-misiones/

La Nación:

http://www.lanacion.com.ar/1199675-musica-del-litoral-rio-polemica-y-terere

\section{Página 12:}

http:/www.pagina12.com.ar/diario/suplementos/espectaculos/2-16002-2009-11-15.html

Cámara de Diputados de la Provincia de Misiones:

http://www.diputadosmisiones.gov.ar/expedientes/docs/2004/proyectos/PR4566.pdf

Youtube:

https://www.youtube.com/watch?v=gXtT968p7V0

Blogspot:

http://lucasbraulioareco.blogspot.com.ar/

Corrientes Chamamé:

http://www.corrienteschamame.com.ar/nuevo/vernota.asp?id_noticia=1506\#.VzosPv197IU 